\title{
Recollection
}

\section{Father of biological cloning in China}

\author{
Zuoyan Zhu ${ }^{1,2}$, Ming $\mathrm{Li}^{3}$, Le Kang ${ }^{3}$ \\ 1 Institute of Hydrobiology, Chinese Academy of Sciences, Wuhan 430072, China \\ 2 College of Life Science, Peking University, Beijing 100871, China \\ ${ }^{3}$ Beijing Institutes of Life Science, Chinese Academy of Sciences, Beijing 100101, China
}

Dizhou Tong (T.C. Tung) is a well-familiar name in China, as there is a story about him in one of the elementary school textbooks. The story describes how he came from a poor family and could not go to middle school until the age of 17 , and how his resolution and diligence made him a successful biologist. But in the academic community, he is remembered and respected for another reason-the outstanding achievement of cross-species cloning in fish.

When talking about the issue of cloning, the first thing that come to the minds of most people is probably the sheep Dolly, the breakthrough in animal cloning by lan Wilmut, Keith Campbell and the collaborators at the Roslin Institute, Scotland in 1997. However, Dolly is not the first cloned animal because the art of animal cloning in vertebrates has been developing for more than half a century. The first successfully cloned vertebrate is a northern leopard frog Rana pipiens, which was done by Robert Briggs and Thomas King through introducing nuclei from cells of the hemisphere blastula into enucleated eggs of the same species in 1952. Nevertheless, people wondered whether a fully differentiated somatic cell would contain the same genetic information as an embryonic cell did, i.e., whether cloning with somatic cells was possible. To answer this question, John Gurdon and his colleagues used the nucleus of an adult intestinal epithelial cell to clone South African frogs Xynopus in 1962, proving that even a well-specialized cell still maintains the full genetic information of developmental totipotency. On the other hand, the incompatibility of nuclei and enucleated eggs among different species had been puzzling experimental biologists.

As an experimental embryologist, during his decades of research experience, Dizhou Tong laid out his research in a wide spectrum including embryology, cell biology and genetics with different models such like sea urchins, amphioxux, and teleosts. No matter what subject he was studying and what techniques he was using, Dizhou Tong was very much curious about the compatibility of nucleus and cytoplasm in embryogenesis and development-did the nucleus alone have all the genetic materials necessary to support the development of an organism? What would happen if the egg nucleus was replaced by another one from different species? He thought of this issue over and over

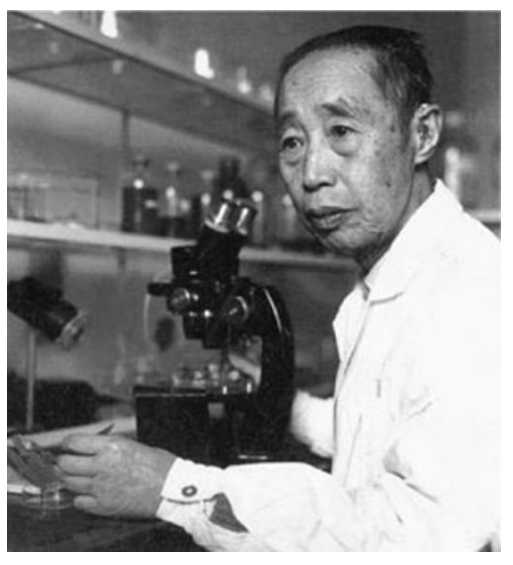

Dizhou Tong

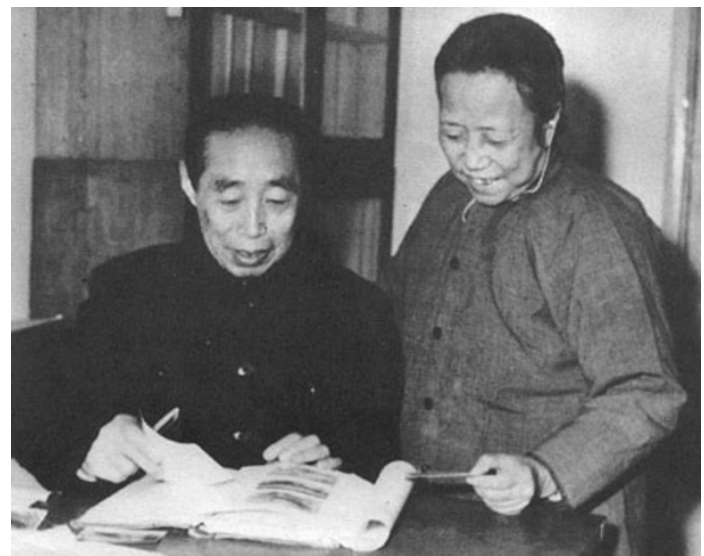

Dizhou Tong and his wife, embryologist Yufen Ye 
again, but the lack of techniques in those years did not allow him to test his curiosity.

When he read the paper about nuclear transplantation performed on amphibians by Briggs and King in 1952, Tong Dizhou realized that the nuclear micro-manipulation of eggs could be an appropriate way to approach his question. In the 1950s when all kinds of resources for research were extremely deficient in China, it was almost impossible to perform highly precise research like nuclear transplantation. After a few years of enduring efforts and countless failures, Tong Dizhou and his colleagues successfully made their own set of micro-manipulator. With this not-so-pretty but very handy equipment, they managed to transfer the nuclei from cells of a male Asian carp to enucleated eggs of a female Asian carp, and therefore, generated the first cloned fish in the world. The cloned fish were perfectly healthy-they developed to full term, swam around and finally produced offspring. This happened in 1963, thirty-four years before Dolly the sheep was born. Sadly, the significance of this study was not recognized by the international scientific community, as the result was only published in Chinese even without English abstract.

Dizhou Tong did not stop at the success of fish cloning. He moved onto the next page-cross-species cloning. Ten years later, in 1973, he and his coworkers isolated nuclei from embryonic cells of a common carp Cyprinus carpio and transferred it into enucleated eggs of crucian carp Carassius auratus. Some of the nuclear-transplants later fully developed into adulthood. It was the first case of cross-species animal cloning in the world! However, the study did not attract much

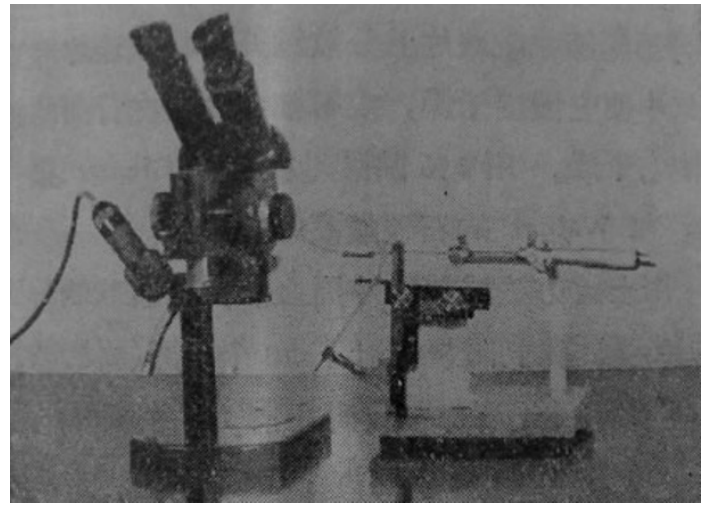

The micro-injection machine designed by Dizhou Tong and his colleagues (From Dizhou Tong Collected, Institute of Developmental Biology, Chinese Academy of Sciences, published by Academic Journal Press, Beijing, 1989. (《童第 周文集》, 中国科学院遗传与发育生物学研究所, 学术期刊出版 社出版, 北京, 1989))

attention as it should have been, due to the difficult circumstances in China in the 1970s. In fact, the result of this study did not get published until 1980, one year after Dizhou Tong passed away. Dizhou Tong was very happy to see the nucleo-cytoplasmic hybrid fish with some distinct characteristics from the nuclear donor species, and dreamed that the novel traits, such as faster growth rate and nutritional contents, would be beneficial to aquaculture in the future. 